\title{
Discovering the Library with Google Earth
}

Libraries need to provide attractive and exciting discovery tools to draw patrons to the valuable resources in their catalogs. The authors conducted a pilot project to explore the free version of Google Earth as such a discover tool for Portland State Library's digital collection of urban planning documents. They created eye-catching placemarks with links to parts of this collection, as well as to other pertinent materials like books, images, and historical background information. The detailed how-to-do part of this article is preceded by a discussion about discovery of library materials and followed by possible applications of this Google Earth project.

I n Calhoun's report to the Library of Congress, it becomes clear that staff time and resources will need to move from cataloging traditional formats, like books, to cataloging unique primary sources, and then providing access to these sources from many different angles. "Organize, digitize, expose unique special collections" (Calhoun 2006).

In 2005, Portland State University Library received a grant "to develop a digital library under the sponsorship of the Portland State University Library to serve as a central repository

Michaela Brenner (brennerm@pdx.edu) is Assistant Professor and Database Maintenance and Catalog Librarian at Portland State University Library, Oregon. Peter Klein (Peter.Klein@ colorado.edu) is Aerospace engineering BS/MS at the University of Colorado at Boulder. of the collection, accession, and dissemination of [urban] key planning documents . . that have high value for Oregon citizens and for scholars around the world" (Abbott 2005). This collection is called the Oregon Sustainable Community Digital Library (OSCDL) and is an ongoing project that includes literature, planning reports, maps, images, RLIS (Regional Land Information System) geographical data, and more. Much of the older material is unpublished, and making it available online presents a valuable resource. Most of the digitized-and, more recently, borndigital-documents are accessible through the library's catalog, where patrons can find them together with other library materials about the City of Portland. The bibliographic records are arranged in the catalog in an electronic resource management (ERM) system (Brenner, Larsen, and Weston 2006). Additionally, these bibliographic data are regularly exported from the library catalog to the OSCDL Web site (http://oscdl. research.pdx.edu) and there integrated with GIS (Global Information System) features, thus optimizing cataloging costs by reusing data in a different electronic environment. Committed to not falling into the trap that Clifford Lynch had in mind when he wrote, "I think there is a mental picture that many of us have that digitization is something you do and you finish . . . a finite, one-time process" (Lynch 2002), and agreeing with Gatenby that "it doesn't matter at all if a user finds our OPAC through the "back door'" (Gatenby 2007), the authors looked into further using these existing data from the library catalog by making them accessible from a popular and appealing place on the Internet, a place that users are more likely to visit than the library catalog.

The free version of Google Earth, a virtual-globe program that can be installed on PCs, lent itself to experimenting. "Google Earth combines the power of Google Search with satellite imagery, maps, terrain and 3-D buildings to put the world's geographic information at your fingertips" (http://earth.google.com). From there, the authors provide links to the digitized documents in the library catalog. Easy distribution, as well as the more playful nature of this pilot project and the inclusion of pictures, make the available data even more attractive to users.

\section{"Google now reigns"}

"Google now reigns," claims Karen Markey (Markey 2007), and many others agree that using Google is easier and more appealing to most than using library catalogs. Google's popularity has been growing spectacularly. In August 2007, Google accounted for 64 percent of all U.S. searches (Avtec Media Group 2007). In contrast, the OCLC report on how users perceive the library shows that only one percent of the respondents begin their information search on a library Web site, while 84 percent use search engines (De Rosa, et al. 2005).

"If we [libraries] want to survive," says Stephen Abram, "we must place our messages where the users are seeking answers and will trip over them. Today that usually means at Yahoo, MSN, and Google" (Abram 2005). According to Lorcan Dempsey, in the longer run, traffic to the library catalog will come by linking from larger consolidated resources, like Open WorldCat and Google Scholar (Dempsey 2005).

Dempsey also stressed that it becomes more and more significant to differentiate between discovery and location (Dempsey 2006a). Initially, users want to discover; they want to find what interests them independent from where this information is actually located and available. While there may be lots of valuable, detailed, and exceptionally well-organized bibliographic information in the library catalog, not 
many users (one percent) are willing to discover this information through the catalog. They may not discover what a library has to offer if "the library does not find a way to go to the user, rather than waiting for the user to come to the library" (Coyle 2007). Unless the intent is to keep our treasures buried, the library community needs to work with popular outside discovery environmentslike search engines-to bring information available in libraries to users from the outside.

Libraries are, although sometimes reluctantly, responding. Google, Google Scholar, and Google Books are Open WorldCat partner sites that are now or soon will be providing access to WorldCat records. Google Book Search includes "Find this book in the library," and the advanced Book Search also has the option to limit a search to library catalogs with access to the WorldCat Web record for each item. "Deep linking" enables Web users to link from search results in Yahoo, Google, or other partner sites to the "Find in a Library" interface in Open WorldCat, and then directly to the item's record in their library's online public access catalog (OPAC). Simply put, "Find it on Google, get it from your library" (Calhoun 2006).

The "leveraged discovery environment" is an expression coined by Dempsey that means it becomes increasingly important to leverage a "discovery environment which is outside your control to bring people back into our catalog environment (like Amazon, Google Scholar)" (Dempsey 2006b).

Issues in Calhoun's report to the Library of Congress include the question of how to get a Google user from Google to library collections. She quotes an interviewee saying that "data about a library's collection needs to be on Google and other popular sites as well as the library interface" (Calhoun 2006).

With evidence pointing to the heavy use of Google for discovery and with Google Earth technology providing such a powerful visualization tool, the authors felt tempted to experiment with existing data from Portland State Library's digital OSCDL collection and make these data accessible through a virtual globe.

\section{The King's College cultural heritage project}

Martyn Jessop from King's College in London, United Kingdom, published an article about a relatively small pilot project on providing access to a digital cultural heritage collection through a geographical information system (Jessop 2005). Jessop's approach to explore different technologies and techniques to apply to existing data about unique primary sources was exactly what the authors had in mind with this project, and provided encouragement to move forward with the idea of providing additional access to the Oregon Sustainable Community Digital Library (OSCDL) collections through Google Earth. Similar to Jessop, the authors regard it an unaffordable luxury to put a great deal of effort into collecting, digitizing, and cataloging materials without making them available to a much broader audience through multiple access points.

Comparable to Jessop, the goal of this project was to find a relatively simple, low-cost technological solution that could also be applied to a much wider range of data without much more investment in staff time and money.

Once the authors mastered the initial hurdle of understanding Google Earth's programming language, they could easily identify with Jessop's notion of "project creep" as more and more possibilities arose to make the project more appealing. This, as with the King's College project, was a valuable part of the development process, the details of which are described below.

\section{The Portland State Library OSCDL-on- Google-Earth project}

The authors chose ten Portlandbased OSCDL sub-collections as the basis of this pilot project: Harbor Drive, Front Street, Portland Public Market, Urban Studies Collection, Downtown, Park Blocks, South Park Blocks, Pioneer Courthouse Square, Portland City Archives, and JPACT (Joint Policy Advisory Committee on Transportation).

The programming language for Google Earth is KML (keyhole markup language), a file format used to display geographic data. KML is based on the XML standard and can be created with the Google Earth user interface or from scratch with a simple text editor. Having no previous KML experience, the authors decided to use both.

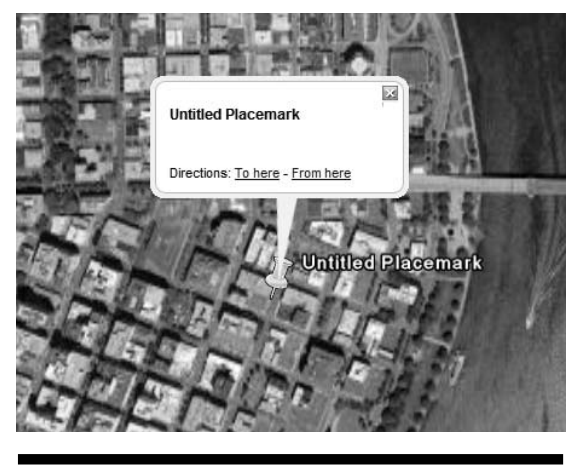

Figure 1. Basic placemark in Google Earth

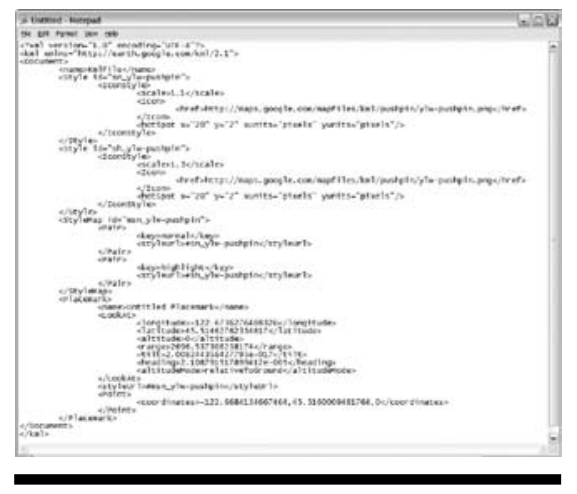

Figure 2. KML script for basic placemark 
A basic placemark provided by Google Earth (figure 1), copied and pasted in Notepad (figure 2), was the starting point.

At Portland State Library, Information Technology routinely batch export cataloged OSCDL data from the library catalog (ILS) to the OSCDL Web site to reuse them. For the Google Earth project, the authors had two options, to either export data relevant to our collections from the ILS to a spreadsheet or to use an existing Excel spreadsheet containing most of the same data, including place coordinates. This spreadsheet was one of many others that had been created to keep track for the digitization process as well as for creating bibliographic records for the library catalog later. Using the available spreadsheet again, the following data were retained:

- the title of the collection

- longitude and latitude of the place the collection refers to

- a brief description of the collection

The following were added manually to the remaining spreadsheet:

- all the texts and URLs for the collection-specific links

- URLs for the collection-specific images

The authors extracted the placemark-specific script from figure 2 to create a template in Notepad. A general description and all links that were the same for the ten collections were added to this template, and placeholders were inserted for collection-specific data (figure 3 ).

Using Microsoft Office Word's mail merge, the authors populated the template with the data from the spreadsheet in one quick step. The result was a KML script that included all the placemark data for the ten collections (figure 4).

The script was saved as plain text (.txt) first, and then renamed with the extension. $\mathrm{kml}$, which represents the final file (figure 5).

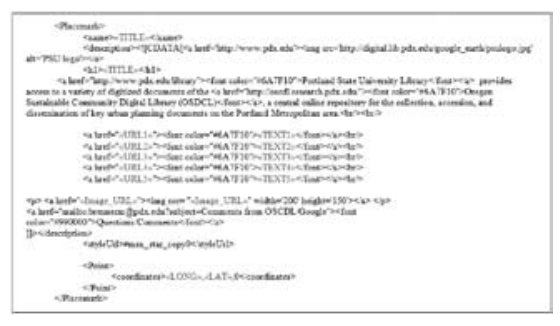

Figure 3. Detail of template with variables between « double brackets »

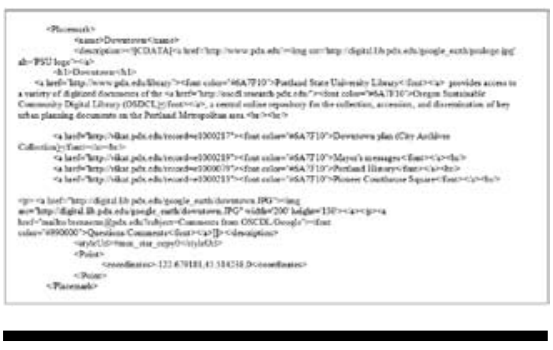

Figure 4. Detail: "Downtown" placemark of finished KML script

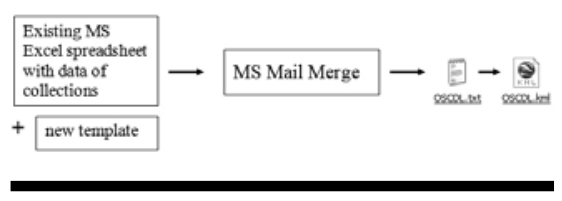

Figure 5. Simplified process

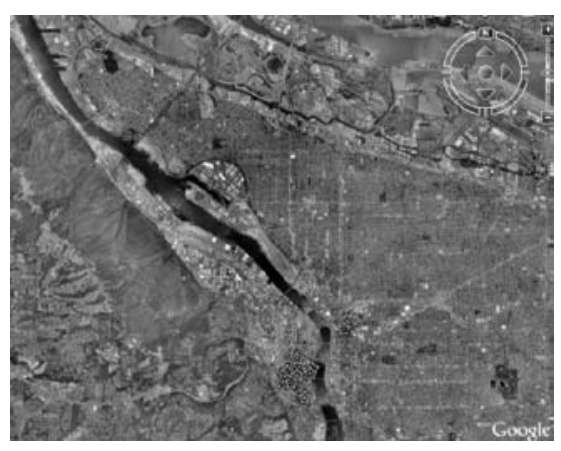

Figure 6. Ten stars representing the ten collections

Clicking the OSCDL.kml icon on a desktop or inside a Web application opens Google Earth. The user "flies" to Portland, where ten stars represent the ten collections (figure 6).
Zooming in, the placemarks show the locations to which the collections refer. Considering the many layers and icons available in Google Earth, the authors decided to use yellow stars to make them more visible. In order to avoid clutter and overlapping labels, titles only appear on mouse-over (figures 7 and 8).

Figure 9 shows the open placemark for Portland Public Market. "Portland State University" with the university's logo is a link that takes the user to the university's homepage. The next line is the title of the collection, followed by a brief description. The paragraph after that is the same for all collections and includes links to the Portland State University Library and the OSCDL Web site. The collection-specific links that follow next go to the library catalog where the user has access to the digitized manuscripts of this collection (figure 10). Other pertinent links-in this case to a book available in the library, a public Web site on the history of the Market, and a historic image of the Market-were added as well. To make the placemarks visually more attractive, all links are presented in the school's "PSU green," and an image representative of the collection was added. The pictures can be enlarged in a new window by clicking on them. To avoid copyright issues, the authors photographed their own images. The last link opens an e-mail window for questions and comments (figure 11).

This link is intended to bring some feedback and suggestions on how to improve the project and on its value for researchers and other users. The authors have been toying with the idea of including in the future more elaborate features such as video clips and music.

One more recent feature is that KML files, created in Google Earth, can now also be viewed on the Web by simply entering the URL of the KML file into the search box of Google Maps (figure 12), thus creating Google Earth placemarks in 


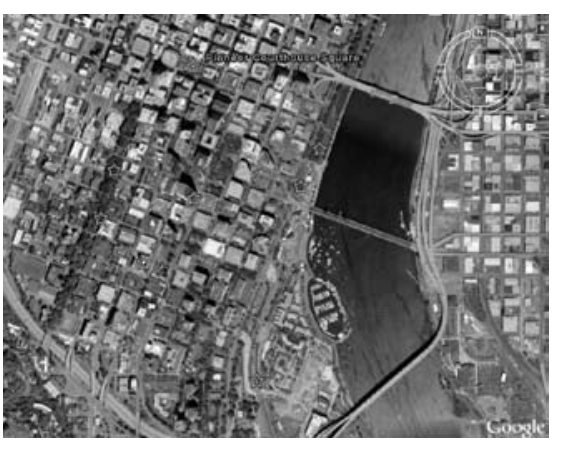

Figure 7. Zoomed in with mouse-over placemark

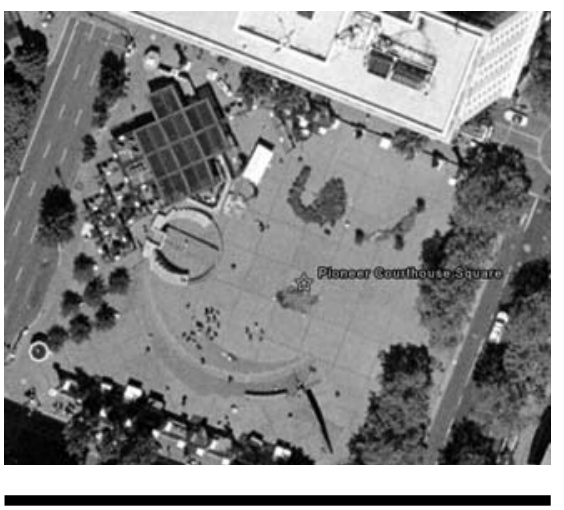

Figure 8. Location of the Pioneer Courthouse Square placemark

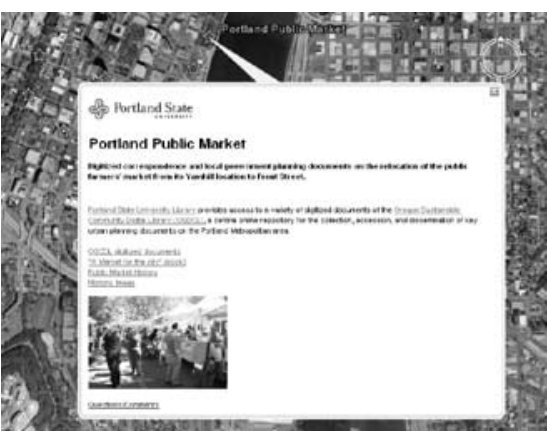

Figure 9. Portland Public Market

Google Maps with different view options (figures 13 and 14). Not all formatting is correctly transferred, and at this point, there is no way to correct this in Google Maps. For example, the yellow stars were white,

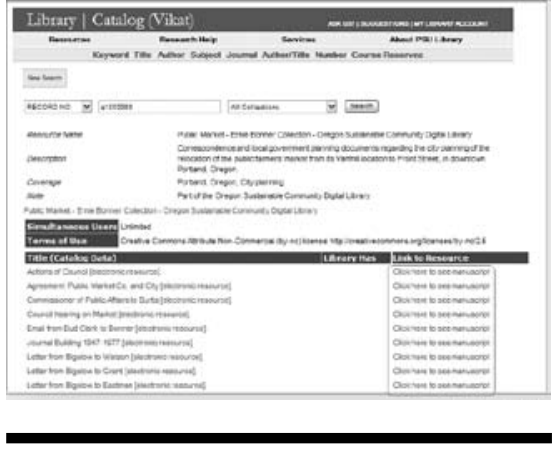

Figure 10. Access to the collection in library catalog

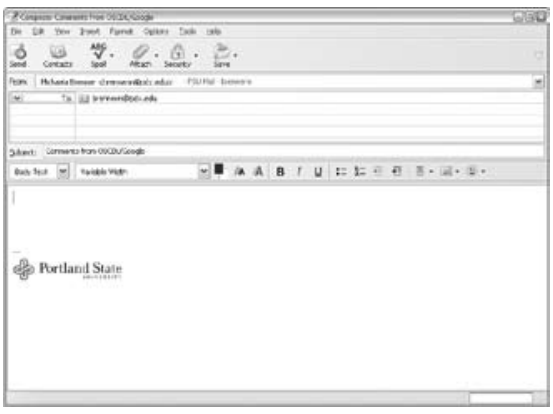

Figure 11. Ready-to-go e-mail window

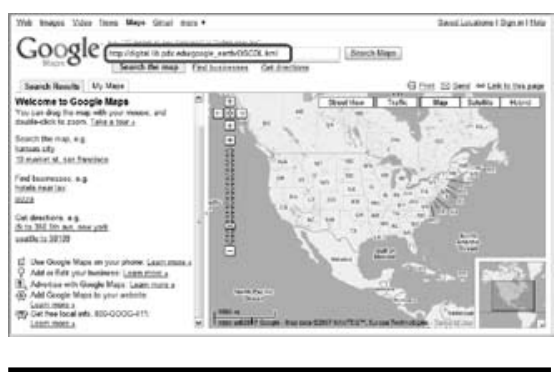

Figure 12. URL of KML file in Google Maps search box

the mouse-over didn't work and the size of the placemarks was imprecise. However, the content of the placemarks-except for the images which didn't show on some computers-was fully retained and all links worked (figure 15). Although the use of the KML file in Google Maps is not as elegant as in Google Earth, it has the advantage that there is no need

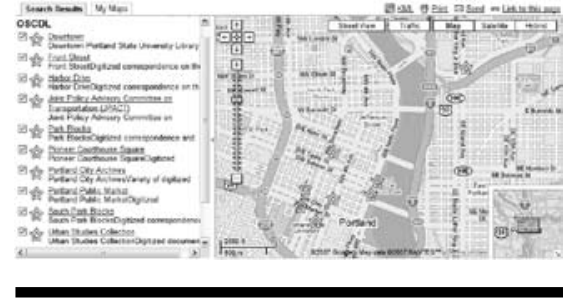

Figure 13. "Map" view in Google Maps

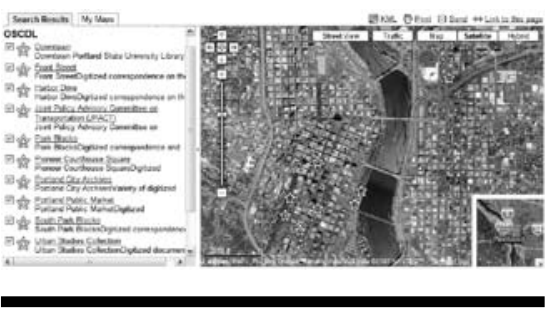

Figure 14. "Satellite" view in Google Maps

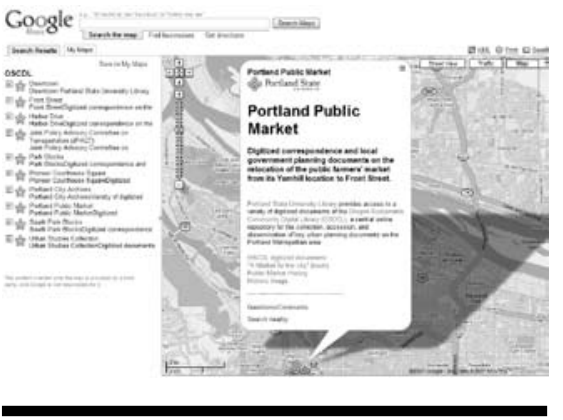

Figure 15. Portland Public Market placemark in Google Maps

to install software as with Google Earth. This adds value to KML files and makes projects like this more versatile.

The authors have identified several uses for the KML file:

- A workstation in the library can be dedicated to resources about the City of Portland. An icon on the desktop of this workstation will open Google Earth and "fly" directly to Portland where the yellow stars are displayed.

- Professors can easily add the .kml file to WebCT (now Blackboard) or other course management systems.

- The file can be e-mailed as an 
attachment to those interested in the development of the City of Portland.

- A link from the Wikipedia page related to the OSCDL project leads to the Google Earth pilot project.

- The project was added to the Google Earth Gallery where many remarkable projects, created by individuals and groups can be found.

- It can also be accessed through the OSCDL Web site, and relevant links from the records in the library catalog to Google Maps can be included. It may be useful to alert patrons, who actually did come to the catalog by themselves, to this visual tool.

\section{Conclusion}

"The question now is not how we improve the catalog as such," says Dempsey. "It is how we provide effective discovery and delivery of library materials in a network environment where attention is scarce and information resources are abundant and where discovery opportunities are being centralized into major search engines and distributed to other environments" (Dempsey 2006a). With this in mind, the authors took on the challenge to create another discovery tool for one of the Library's primary unique digital collections.

Google Earth is not the Web, and it needs to be installed on a workstation in order to use a KML file. On the other hand, the file created in Google Earth can also be used on the Web more readily but less elegantly in Google Maps, thus possibly reaching a larger audience.

Similar to the King's College project and following Abram's suggestion that "we should experiment more with pilots in specific areas" (Abram 2005), this pilot project is of an exploratory, experimental nature. And as with many experiments, the authors were testing an idea, trying something different and new to find out how useful this idea might be, and useful applications for this project were identified. Google Earth is a sophisticated, attractive, and exciting program-and fun to play with. In a time "where attention is scarce and information resources are abundant," as Dempsey (2006a) says, we need to provide these kinds of discovery tools to attract patrons and to lure them to these valuable resources in our library's catalog that we created with so much diligence and cost of staff time and resources.

\section{Works Cited}

Abbott, Carl. 2005. Planning a sustainable Portland: A digital library for local, regional, and state planning and policy documents. Framing paper. http:/ / oscdl.research.pdx.edu/documents/library_grant.pdf.

Abram, Stephen. 2005. The Google opportunity. Library Journal 130, no. 2: 34.

Avtec Media Group. 2007. Search engine statistics. http://avtecmedia.com/ internet-marketing/internet-marketing-trends.htm.

Brenner, Michaela, Tom Larsen, and Claudia Weston. 2006. Digital collection management through the library catalog. Information Technology and Libraries 25, no. 2: 65-77.

Calhoun, Karen. 2006. The changing nature of the catalog and its integra- tion with other discovery tools; final report, prepared for the Library of Congress. www.loc.gov.proxy.lib.pdx. edu/catdir/calhoun-report-final.pdf.

Coyle, Karen. 2007. The library catalog in a 2.0 world. The Journal of Academic Librarianship 33, no. 2: 289-291.

De Rosa, Cathy et al. 2005. Perceptions of libraries and information resources. A report to the OCLC membership. www .oclc.org.proxy.lib.pdx.edu/reports / pdfs/Percept_all.pdf.

Dempsey, Lorcan. 2006a. The library catalogue in the new discovery environment: Some thoughts. Ariadne 48. www.ariadne.ac.uk/issue $48 /$ dempsey.

Dempsey, Lorcan. 2006b. Lifting out the catalog discovery experience. Lorcan Dempsey's Weblog on Libraries, Services, and Networks, May 14, 2006. http://orweblog .oclc.org/archives/001021.html

Dempsey, Lorcan. 2005. Making data work-Web 2.0 and catalogs. Lorcan Dempsey's Weblog on Libraries, Services, and Networks, October 4, 2005. http://orweblog.oclc .org/archives/000815.html

Gatenby, Janifer. 2007. Accessing library materials via Google and other Web sites. Paper presented to ELAG (European Library Automation Group), May 9, 2007. http://elag2007.upf. edu/papers/gatenby_2.pdf.

Jessop, Martyn. 2005. The application of a geographical information system to the creation of a cultural heritage digital resource. Literary and Linguistic Computing: Journal of the Association for Literary and Linguistic Computing 20, no. 1: 71-90.

Lynch, Clifford. 2002. Digital collections, digital libraries, and the digitization of cultural heritage information. First Monday 7, no. 5. www.firstmonday. org/issues/issue7_5/lynch.

Markey, Karen. 2007. The online library catalog.D-LibMagazine13,no.1/2.www .dlib.org/dlib/january07/markey/01 markey.html.

Index to Advertisers

LITA cover 2, cover 3, cover 4 